\title{
Comparing Spray Gun and Spray Boom Applications in Two Ivy Crops with Different Crop Densities
}

\author{
Dieter Foqué ${ }^{1}$ \\ Institute for Agricultural and Fisheries Research (ILVO), Technology and \\ Food Science Unit, Agricultural Engineering, Burg. Van Gansberghelaan \\ 115, bus 1, 9820 Merelbeke, Belgium
}

Jan G. Pieters

Ghent University, Department of Biosystems Engineering, Faculty of Bioscience Engineering, Coupure links 653, 9000 Ghent, Belgium

\section{David Nuyttens ${ }^{1}$ \\ Institute for Agricultural and Fisheries Research (ILVO), Technology and Food Science Unit, Agricultural Engineering, Burg. Van Gansberghelaan 115, bus 1, 9820 Merelbeke, Belgium}

Additional index words. Hedera helix, spray nozzle, spray gun, spray boom, plant protection, spray deposition

\begin{abstract}
Flemish greenhouse growers predominantly use handheld spray guns and lances for their crop protection purposes despite the heavy workload and high risk for operator exposure associated with these techniques. These spray application techniques have also shown to be less effective than spray boom equipment under many conditions. Handheld spraying techniques are less expensive, however, and they are more flexible in practical use. Many growers also erroneously believe that high spray volumes and pressures are needed to assure good plant protection. The aim of this work was to evaluate the spray deposition, penetration, and uniformity between a manually pulled horizontal spray boom as compared with a spray gun under controlled laboratory conditions. In this study, we evaluated six spray application techniques, i.e., three spray boom and three spray gun techniques. In general, the deposition results were comparable between the spray boom and the spray gun applications. The spray boom applications, however, resulted in a more uniform spray distribution. At the plant level, the spray distribution was not uniform for any of the techniques used; the highest deposits were observed on the upper (or adaxial) side of the top leaves. Using spray guns at a higher spray pressure did not improve spray penetration in the canopy or deposition on the bottom (or abaxial) side of the leaves. Of the different nozzle types tested on the spray boom, the extended range flat fan XR 8003 gave the best results. Crop density clearly affected crop penetration and deposition on the bottom side of the leaves.
\end{abstract}

In 2004, a survey of Flemish ornamental plant growers revealed that they predominantly use knapsack sprayers and lances to spray pesticides (Braekman and Sonck, 2008). These techniques are known for being labor-intensive and having a high risk of operator exposure

Received for publication 25 Aug. 2011. Accepted for publication 28 Oct. 2011.

We thank the Flemish Government (IWT Vlaanderen) for financial support of this project. We also acknowledge our research partner, the Research Centre for Ornamental Plants (PCS, Destelbergen, Belgium), for their help during the 4 project years. We thank ILVO's technical staff for the construction and maintenance of the various prototypes constructed in the project; Thijs De Baere for conducting most of the spray boom applications; Donald Dekeyser, Eva Brusselman, and Veerle Van linden for proofreading the article; and Miriam Levenson for English-language assistance.

${ }^{1}$ To whom reprint requests should be addressed; e-mail dieter.foque@ilvo.vlaanderen.be or david.nuyttens@ ilvo.vlaanderen.be.
(González et al., 2009; Moltó et al., 2000; Nuyttens et al., 2009a; Sánchez-Hermosilla et al., 2003; Subramanian et al., 2005; Vidal et al., 2002). Additionally, their spray results are generally less uniform as compared with spray boom equipment (Braekman et al., 2009, 2010; Derksen et al., 2010; Langenakens et al., 2002;
Moltó et al., 2000; Nuyttens et al., 2004, 2009a; Sánchez-Hermosilla et al., 2011). The handheld spraying techniques have several advantages, however; they are inexpensive, flexible to use, easy to maintain, and adequate for controlling small-scale, localized phytosanitary problems (Sánchez-Hermosilla et al., 2011).

In addition, growers erroneously believe that a high spray volume (up to $6650 \mathrm{~L} \cdot \mathrm{ha}^{-1}$ ) and pressure (5000 $\mathrm{kPa}$ and more) are needed for good plant protection (Braekman and Sonck, 2008; Goossens et al., 2004), but new surveys (Braekman and Sonck, 2008; Vissers, 2005) have shown that growers still encounter persistent diseases and pests. As the growers have continued to use similar equipment since 2004, it appears that these application techniques are insufficient for crop protection purposes (Braekman and Sonck, 2008). Furthermore, Braekman et al. (2010) proved that using small-sized extended-range flat fan nozzles at a pressure above the recommended pressure range, a common practice among Flemish greenhouse growers, resulted in significantly lower depositions, especially inside the canopy. This is in agreement with findings of SánchezHermosilla et al. (2011), who described that the lack of uniformity from spray guns is the result of the combined effect of inadequate penetration in the canopy, heavy losses to the ground from leaf runoff, and insufficient deposition on the underside (or abaxial) of the leaves. These findings confirm that using a higher spray volume or pressure cannot guarantee better spray results. As a reaction to insufficient pest control, the growers usually spray more frequently using the same a.i. and a higher spray volume. Almost all plant protection products authorized for greenhouse ornamental plants in Belgium express the dose as a concentration (e.g., $50 \mathrm{~g}$ per $100 \mathrm{~L}$ spray volume; <http:// www.fytoweb.be $>$ ). Increased frequency of spraying and higher spray pressures and volumes therefore increase environmental pollution, operator exposure risks, and the risk to develop resistance. Spray boom systems have the potential to resolve many of these problems because they perform better, even at higher speeds, and they can be operated automatically. Despite growing acceptance and use of spray boom systems (Braekman and Sonck, 2008; Goossens et al., 2004), many growers remain unconvinced of their efficacy and do not use them. The growers using spray boom
Table 1. Spray application techniques and parameters for the six trials.

\begin{tabular}{|c|c|c|c|c|c|c|}
\hline $\begin{array}{l}\text { Application } \\
\text { technique }\end{array}$ & Nozzle type & $\begin{array}{c}\text { Traveling } \\
\text { speed } \\
\left(\mathrm{km} \cdot \mathrm{h}^{-1}\right)\end{array}$ & $\begin{array}{l}\text { Nozzle } \\
\text { flow rate } \\
\left(\mathrm{L} \cdot \mathrm{min}^{-1}\right)\end{array}$ & $\begin{array}{c}\text { Number } \\
\text { of } \\
\text { nozzles }\end{array}$ & $\begin{array}{c}\text { Spray } \\
\text { pressure } \\
(\mathrm{kPa})\end{array}$ & $\begin{array}{c}\text { Spray } \\
\text { volume } \\
\left(\mathrm{L} \cdot \mathrm{ha}^{-1}\right)\end{array}$ \\
\hline \multirow[t]{2}{*}{ Spray boom $1^{\mathrm{y}}$} & Extended flat & 2.82 & 1.18 & 6 & 300 & $971 \pm 44^{x}$ \\
\hline & fan XR 8003 & 3.01 & 1.18 & 3 & 300 & \\
\hline \multirow[t]{2}{*}{ Spray boom $2^{y}$} & Hollow cone & 3.06 & 1.18 & 6 & 300 & $981 \pm 76^{\mathrm{x}}$ \\
\hline & TXA 8003 & 2.74 & 1.18 & 3 & 300 & \\
\hline \multirow[t]{2}{*}{ Spray boom $3^{y}$} & Air inclusion flat & 2.76 & 1.09 & 6 & 600 & $1030 \pm 110$ \\
\hline & fan ID 9002 & 2.37 & 1.09 & 3 & 600 & \\
\hline Spray gun 1 & Orifice disc & 1.60 & 10.30 & 1 & $1500^{z}$ & 1794 \\
\hline Spray gun $2^{y}$ & Orifice disc & 0.84 & 3.04 & 1 & $700^{z}$ & 1007 \\
\hline Spray gun 3 & Orifice disc & 1.86 & 8.05 & 1 & $1000^{z}$ & 1209 \\
\hline
\end{tabular}

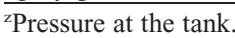

${ }^{y}$ Spray application performed by an inexperienced operator.

${ }^{\mathrm{x}}$ The spray volume of the spray boom applications, presented as the mean of the two runs (mean $\pm \mathrm{SD}$ ). 
systems often have questions about application technique, equipment maintenance, optimal settings, nozzle type, and so on.

To address some of those questions, we researched the optimization of spraying equipment and technology used in ornamental crops (conducted at ILVO, 2006-2011). Initially, manually operated, inexpensive prototypes were built (Braekman and Sonck, 2008; Foqué and Nuyttens, 2010), then horizontal (Foqué and Nuyttens, 2011a, 2011b) as well as vertical spray boom applications (Foqué et al., 2011c; Nuyttens et al., 2009b) were optimized and tested in ILVO's Spray Tech Laboratory (<http://www.ilvo.vlaanderen.belspraytechlab $>$ ). The current study continues that work. The aim of this study was to investigate if the use of simple spray boom systems can improve deposition and penetration in the crop and the uniformity of the spray liquid distribution as compared with the traditional spray gun applications in ornamental crops. Under laboratory conditions, the spray deposition, penetration, and uniformity of the spray applied using a manually pulled horizontal spray boom was evaluated and compared with spray gun applications. The potential effect of the crop's density was taken into account as well.

\section{Materials and Methods}

Spray application techniques and parameters. In total, six applications were made using various application techniques and parameters (Table 1).

As a result of the width of the experimental setup (2.10 m) (Fig. 1) and the dimensions of the manually operated horizontal boom (width of 1 spray arm $=1.50 \mathrm{~m}$ ) (Fig. 2), two spray runs were necessary to cover the entire targeted area (Fig. 1). In one run, six nozzles were used and in the other three. Both applications were performed in the same direction. The nozzle types, the nozzle spacing $(0.25 \mathrm{~m})$, the spray boom height above the crop $(0.45 \mathrm{~m})$, and the intended traveling speed $\left(2.7 \mathrm{~km} \cdot \mathrm{h}^{-1}\right)$ were selected based on laboratory trials (Foqué and Nuyttens, 2011a) and resulted in an application volume of $\approx 1000 \mathrm{~L} \cdot \mathrm{ha}^{-1}$. Although these laboratory trials showed that the use of an appropriate spray angle and air support can significantly enhance the performance of horizontal spray boom techniques (Foqué and Nuyttens, 2011a, 2011b), only basic spray boom techniques and settings were tested in this study to investigate whether they can improve on the traditional handheld techniques.

Three spray gun applications were made: two by experienced greenhouse growers using their own settings as they would do for a similar crop in normal greenhouse conditions and the third by an inexperienced operator. The spray parameters of this third application were set to result in a spray volume of $\approx 1000 \mathrm{~L} \cdot \mathrm{ha}^{-1}$ in correspondence with the spray boom applications in this experiment.

Experimental setup. Ivy pot plants (Hedera helix, pot size $13 \mathrm{~cm}$ ) with an approximate height of $15 \mathrm{~cm}$ were sprayed. These plants were arranged in two blocks of 60 plants (Figs. 1 and 3).

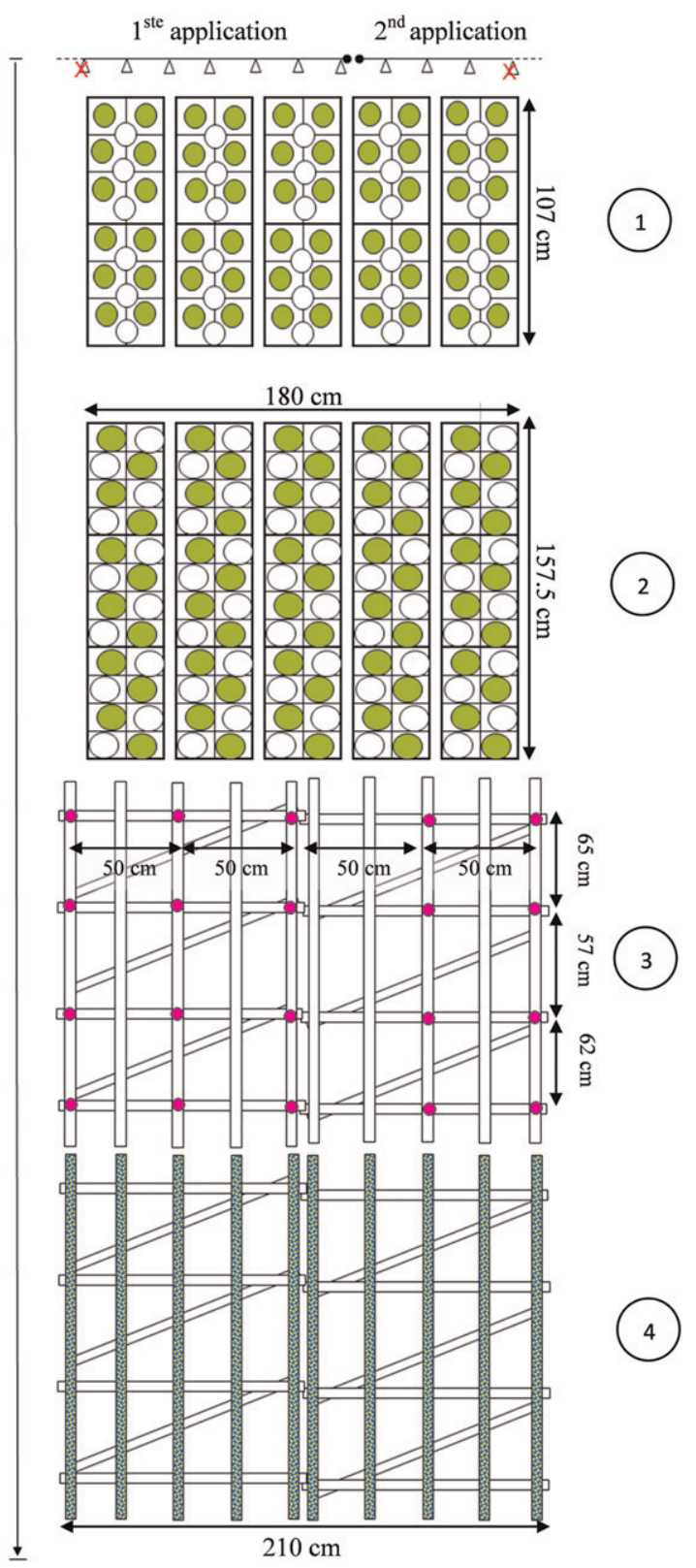

Fig. 1. Schematic of the experimental setup: (1) ivy crop with a high density, (2) ivy crop with a low density, (3) wooden frame with 20 filter paper collectors, (4) wooden frame equipped with large strips of water sensitive paper.

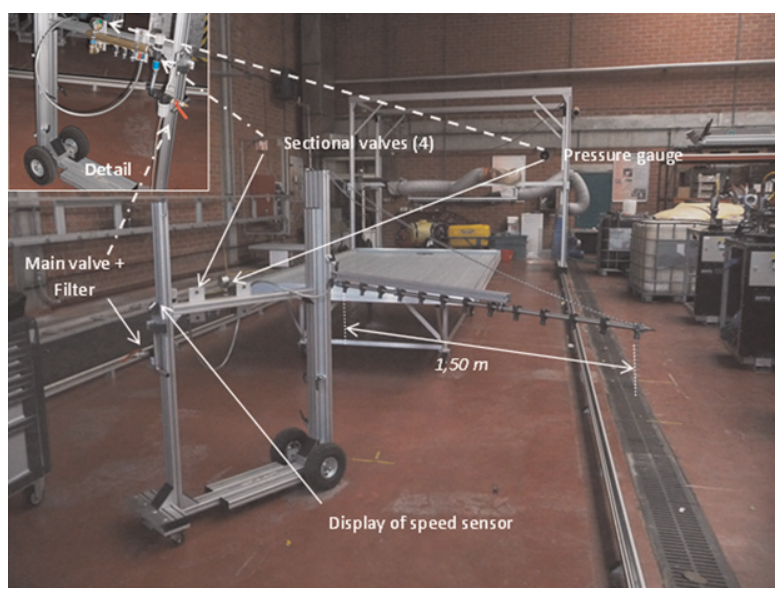

Fig. 2. Prototype of a manually pulled spray boom. 

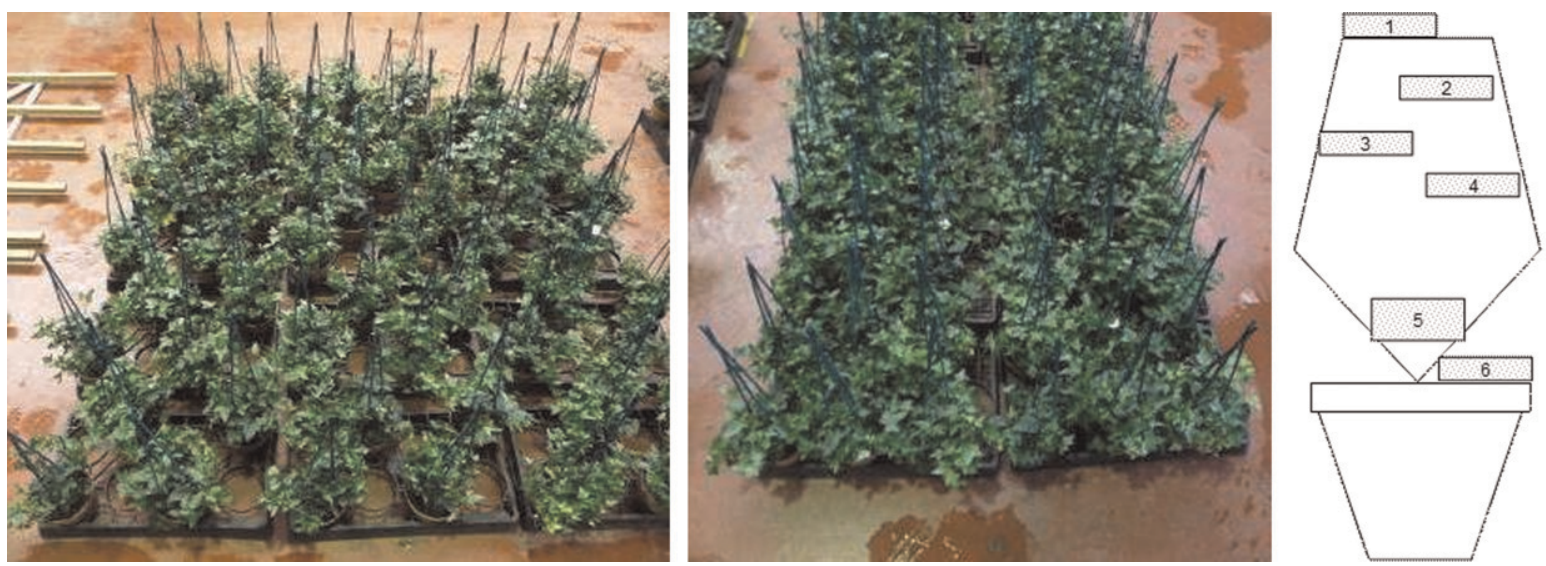

Fig. 3. (Left) Low-density crop (21 plants $\left./ \mathrm{m}^{2}\right)$, (middle) high-density crop (32 plants $\left./ \mathrm{m}^{2}\right)$, and (right) schematic of one collector plant showing the different collector positions: 1 = upper layer, upper side of leaf; $2=$ upper layer, underside of leaf; $3=$ middle layer, upper side of leaf; $4=$ middle layer, underside of leaf; 5 = ground level, attached to stem; and 6 = ground level, horizontal to soil, on top of a small petri dish.

The crop with a higher density was set up using two rows of nine-holed trays $(31 \mathrm{~cm} \times 52$ $\mathrm{cm}$, Fig. 1, 1) with six ivy plants in each tray. Uniform distribution of these plants was created by leaving a $5-\mathrm{cm}$ open space between each tray perpendicular to the spray boom direction. This setup resulted in a density of 32 plants $/ \mathrm{m}^{2}$.

The crop with a lower density was set up using three rows of eight-holed trays $(32 \mathrm{~cm} \times$ $53 \mathrm{~cm}$, Fig. 1, 2) with four ivy plants in each tray. Again, a 5-cm open space was left between each tray with the opening oriented perpendicular to the spray. This setup resulted in a density of 21 plants $/ \mathrm{m}^{2}$.

Deposition measurements. The different spray application techniques were compared using the mineral chelate tracer method (Foqué and Nuyttens, 2011a, 2011b). In each crop block, six plants were equipped with filter paper collectors $(1.9 \mathrm{~cm} \times 2.6 \mathrm{~cm}$, Schleicher \& Schuell Type 751; Filter Service NV, Eupen, Belgium). These collectors were attached to the plants at six different positions in the plant (Foqué and Nuyttens, 2011a, 2011b) (Fig. 3, right).

In addition, 20 filter paper collectors (7.6 $\mathrm{cm} \times 2.6 \mathrm{~cm}$, Schleicher \& Schuell Type 751 ; Filter Service NV) were attached to a wooden frame positioned outside the crop (Fig. 1, 3). This setup was used to evaluate the homogeneity of the liquid distribution of the different techniques.

The chelated minerals boron, iron, copper, cobalt, manganese, and zinc, all commercially available as leaf fertilizers (BMS Micronutrients NV, Bornem, Belgium), were used as tracers. These minerals were sprayed with a concentration of $\approx 1 \mathrm{~g} \cdot \mathrm{L}^{-1}$. The exact concentration of the tank solution and the recovery was checked by pipetting a $200-\mu \mathrm{L}$ subsample of the spray liquid, sampled at the nozzles, onto four collectors.

The same filter paper collectors were used for all spraying events. The sprayed collectors were allowed to dry before being sprayed again. After completing all sprays, the completely dry collectors were recovered and kept in labeled petri dishes $(\varnothing 9.0 \mathrm{~cm})$. Filter paper collectors were analyzed by inductively

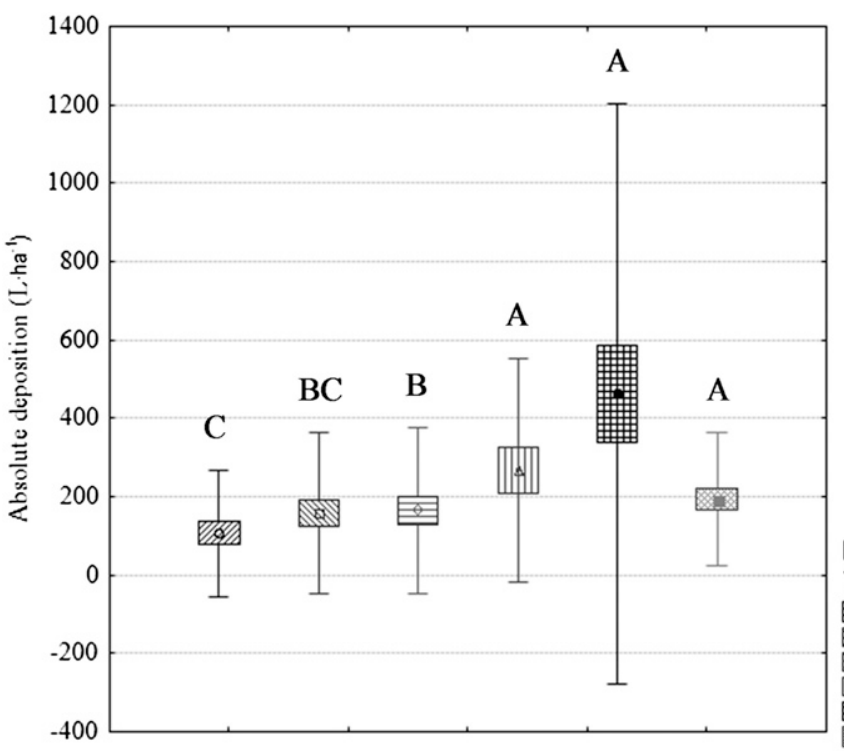

$\mathbf{A}$

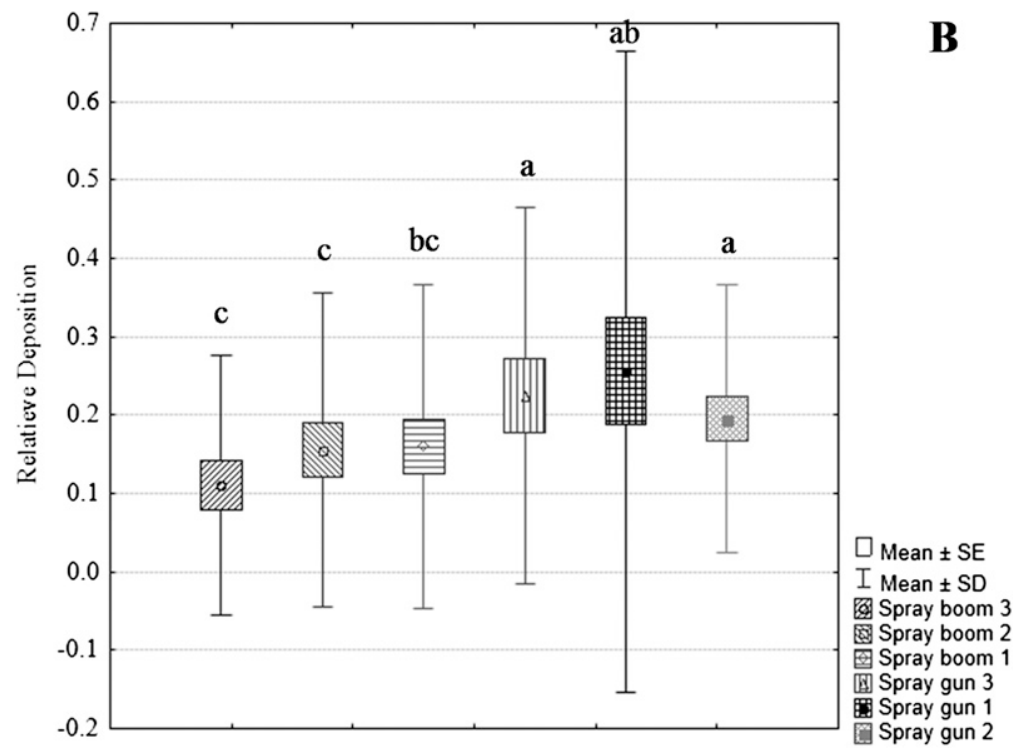

Fig. 4. (A) Absolute $\left(\mathrm{L} \cdot \mathrm{ha}^{-1}\right)$ and (B) relative (\%) spray depositions of the different application techniques in a low-density ivy crop. Bars carrying the same letter are not statistically significant $(P<0.05)$. 
coupled plasma analysis, after extraction $(6 \mathrm{~h})$ of minerals in $20 \mathrm{~mL} 16 \mathrm{~N}^{-\mathrm{HNO}_{3}}$ (nitric acid).

Coverage. Long strips of water-sensitive paper $(50 \mathrm{~cm} \times 2.6 \mathrm{~cm})$ (Fig. 1, 4) were placed on a wooden frame to provide more information about the homogeneity and coverage of the liquid distribution. These strips were replaced after every spray application. The strips were allowed to dry after which they were put into labeled polyethylene zip bags (18 cm $\times 12 \mathrm{~cm}$; Overtoom, Ternat, Belgium) and stored in a dry place to prevent them from further discoloration. This allowed analysis of these collectors by image processing at a later time. On visual assessment, however, it became clear that all the collectors were almost completely blue as a result of the high spraying volumes and merging droplets. This was true for all techniques. This prevented further analysis of these collectors.

Statistical analysis. Statistica 9.1 (Statsoft Inc., Tulsa, OK) was used for all statistical analysis. A $P$ value $<0.05$ was considered statistically significant.

Because the spray volumes were not normally distributed (Shapiro-Wilk's W $=0.69$, $P=0.01$ ), the significance of the differences between the application rates of the different techniques was checked by comparing the observed spray volumes with the expected volumes (goodness of fit). Because the differences proved to be significant $\left[\chi_{(\mathrm{df}=5)}=\right.$ 676.27, $P<0.001]$, the statistical analysis of the spray deposition results was done based on the absolute $\left(\mathrm{L} \cdot \mathrm{ha}^{-1}\right)$ as well as the relative (\%) deposits.

Separate analyses were performed on the collectors in the low-density crop, the highdensity crop, and on the wooden frame. First, a factorial analysis of variance (ANOVA) was used to evaluate how the tested techniques influenced the deposition on different layers of the crop. Some preliminary analyses indicated that the logarithmically transformed [natural logarithm: = Ln (x)] data set of the absolute and relative deposition was most suitable to facilitate such an analysis. After transformation and removal of the outliers and extreme values (done for each technique separately), a factorial ANOVA was used for both the relative and absolute deposition data. Because the interaction term technique $\times$ collector position was never significant, main effect ANOVAs were used. The influence of crop density on deposition in the crop was also examined using factorial ANOVAs.

The initial analysis of the deposits on the frame collectors showed that the relative data set (W $=0.98, P=0.06$ ) was normally distributed, whereas the absolute data set $(\mathrm{W}=$ $0.96, P<0.01)$ was not. The high $\mathrm{W}$-value and further investigation of this data set, however, proved that the data per technique were normally distributed. We therefore used ANOVAs for all further statistical analysis. Because of the experimental design, no factorial ANOVA could be used (no repetitions per technique per collector position). Further testing was done based on main effect ANOVAs.

\section{Results and Discussion}

Spray volume. Although all spray applications were meant to result in an equal spray volume of $\approx 1000 \mathrm{~L} \cdot \mathrm{ha}^{-1}$, significant differences were observed in the actual spray volumes used because of variations in traveling speed (Table 1). When compared with the technique with the lowest application rate, i.e., the spray boom equipped with extended flat fan nozzles (XR 8003), the other two boom applications (TXA 8003, ID 9002), and the spray gun 2 application differed by a factor of 1.01, 1.06, and 1.04 , respectively. The deviation of the other spray gun applications was larger: 1.25 for the spray gun 3 application and 1.85 for the spray gun 1 application. For the ivy crop with a lower crop density, the main effect ANOVAs indicated differences between the techniques based on the absolute $\left[\mathrm{F}_{(5,185)}=9.66, P<0.01\right]$ as well as on the
Spray deposition in the low-density ivy crop. relative $\left[\mathrm{F}_{(5,185)}=5.52, P<0.01\right]$ depositions (Fig. 4).

Despite some variation within the two types of application, the absolute deposition data reveal that the spray guns performed better than the spray boom applications. Within the boom applications, the spray boom 1 (XR 8003 ) and 2 applications (TXA 8003) showed significantly higher depositions than the spray boom 3 application (ID9002). When the spray volumes (relative depositions) were taken into account, the significant difference between the spray boom 1 application and the spray gun 1 application disappears, most likely as a result of the large error bars of the spray gun 1 application and the slightly higher relative deposition of the spray boom 1 application compared with the other boom applications. Nevertheless, all boom applications proved to be statistically equal and the spray gun applications still resulted in higher depositions. This suggests
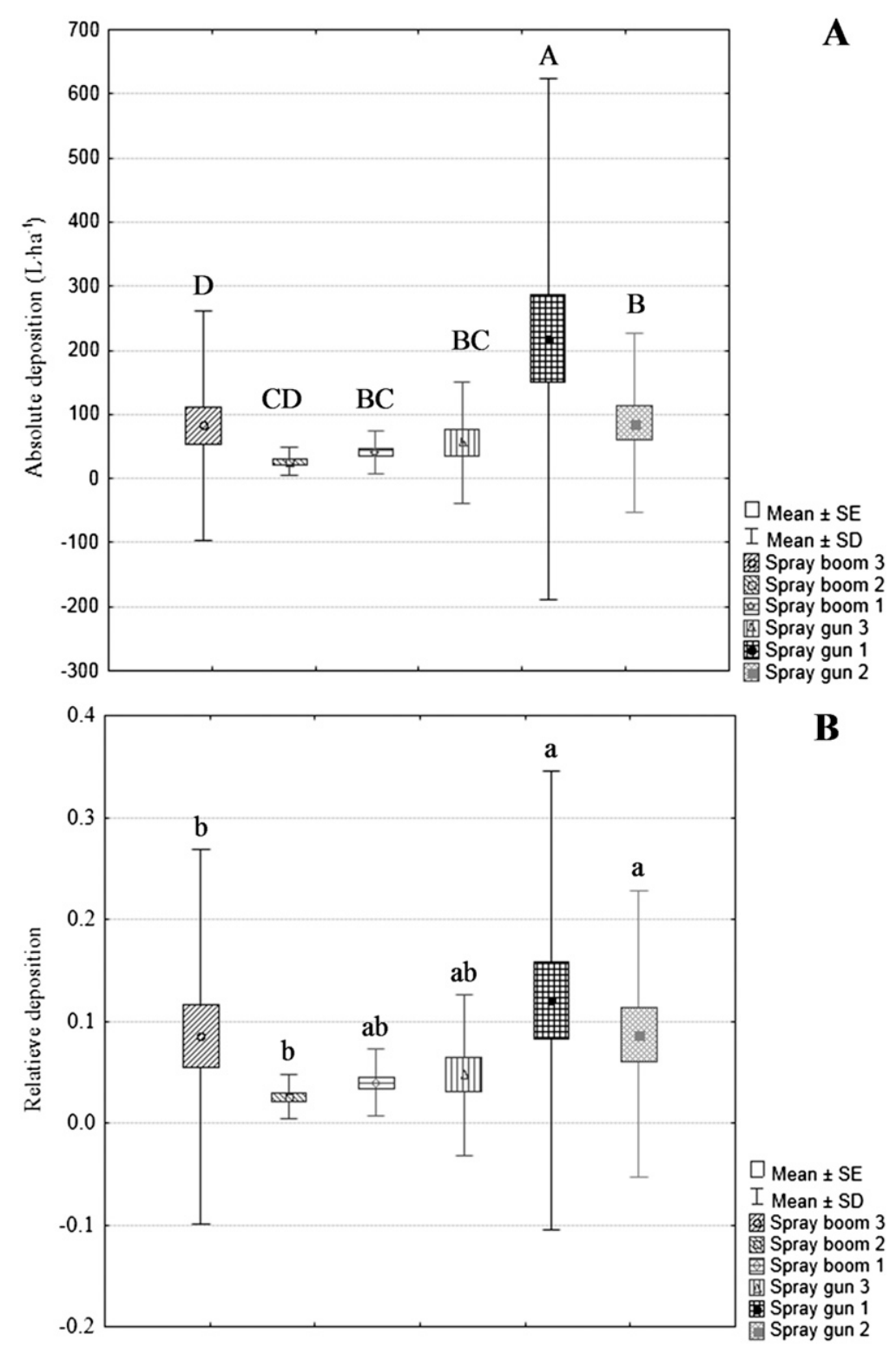

Fig. 5. (A) Absolute (L.ha ${ }^{-1}$ ) and (B) relative (\%) spray depositions of the different application techniques in a high-density ivy crop. Bars carrying the same letter are not statistically significant $(P<0.05)$. 
that spray gun applications can be beneficial in a low-density crop.

Except for spray gun 2, the spray guns showed larger error bars, even when depositions are expressed relative to the application rate. This suggests that spray gun applications mostly result in a less homogenous spray distribution.

Spray deposition in the high-density ivy crop. In the high-density crop (Fig. 5A), the standard XR 8003 boom applications performed equally to the spray guns, except for spray gun 1, which still showed a higher absolute deposition as a result of its high spray volume $\left[\mathrm{F}_{(5,170)}=8.79 ; P<0.01\right]$. Spray guns 1 and 3 resulted in depositions equal to those made by the spray boom 1 application. The absolute depositions of spray gun 3 are even statistically similar to the ones of the spray boom 2 application, which had a slightly lower (not significant) deposition compared with the spray boom 1 application. A comparable absolute deposition was found for the spray boom 2 and 3 applications.

Conversely, when the results are expressed as a relative deposition $\left[\left(\mathrm{F}_{(5,170)}=\right.\right.$ 4.27; $P<0.01$ ] (Fig. 5B), these differences disappear. Spray gun 3 was found to be statistically equal to all spray boom applications. Because all spray guns show a comparable spray result, no positive effect of an increase in spray pressure or spray volume was seen. This disproves the belief that these higher pressures and application rates are needed for good deposition and penetration in a dense canopy.

The spray boom applications also resulted in a more uniform spray distribution in the canopy. With the exception of the ID9002 nozzle types, the boom applications showed smaller error bars, indicating a more uniform distribution, for the absolute as well as the relative depositions.

Effect of crop density on the spray distribution within the crop. The crop density appears to influence depositions in the crop (Figs. 4 and 5; performance of the various techniques, shown previously). The significance of the density of the crop was examined using factorial ANOVAs and the logarithmic transformed data set of all techniques. Both the absolute $\left[\mathrm{F}_{(5,347)}=2.87 ; P=0.01\right]$ as well as the relative $\left[\mathrm{F}_{(5,347)}=3.09 ; P=0.01\right]$ depositions showed significant differences. The post hoc tests of each of these analyses led to the same conclusion (Fig. 6). Significantly lower depositions were measured on the upper (or adaxial) side of the leaves in the upper and the middle layer of the highdensity crop (positions 1 and 3) compared with the low-density crop. Although the deposition on the other plant collectors was also highest in the low-density crop, they are not significantly different from those observed in the high-density crop. The lower depositions on the collectors oriented upward in the top layer (position 1) could be the result of increased runoff caused by a more compact canopy. The lower depositions on the upper side of leaves in the middle of the canopy (position 3 ) result from lower pene-

Collector Position * Density Crop

$$
F_{(5,347)}=2.87, p=0.02
$$

Vertical bars denote 0.95 confidence intervals

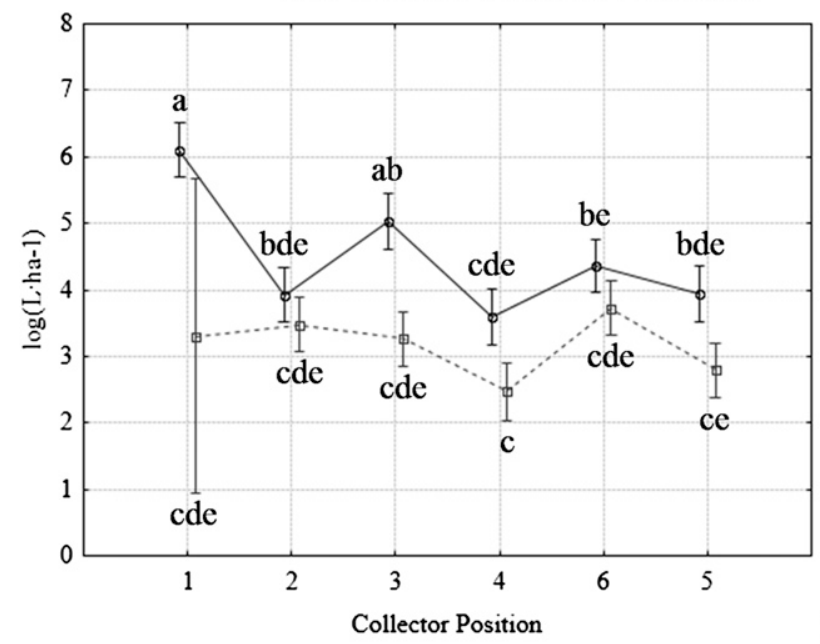

Collector Position * Density Crop

$F_{(5,347)}=3.09, p=0.01$

Vertical bars denote 0.95 confidence intervals

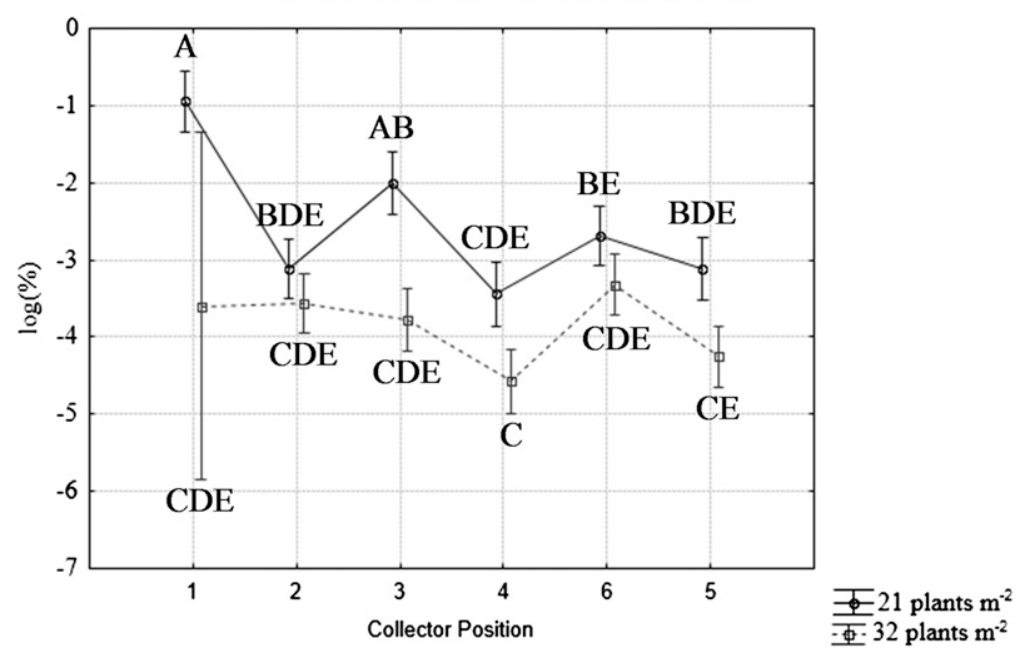

Fig. 6. (A) Absolute $\left[\log \left(\mathrm{L} \cdot \mathrm{ha}^{-1}\right)\right]$ and $(\mathbf{B})$ relative $[\log (\%)]$ deposition measured at different positions in a low- and high-density ivy crop. 1 = upper layer, upper side of leaf; 2 = upper layer, underside of leaf; 3 = middle layer, upper side of leaf; $4=$ middle layer, underside of leaf; $5=$ ground level, attached to stem; and $6=$ ground level, horizontal to soil, on top of a small petri dish. Bars carrying the same letter are not statistically significant $(P<0.05)$.

tration of the spray. Both deposition results are a direct consequence of the higher crop density.

This can be explained as follows: at first, as a result of the dense canopy, the spray cannot penetrate into the crop. Therefore, many droplets are deposited onto the outer edges of the crop. These leaves receive so much liquid at once that runoff occurs. As a result, the excess spray liquid either travels downward along the stem or amalgamated droplets start dripping from the edge of the leaves. These bigger droplets are unlikely to be deposited on another part of the plant because large drips have a higher probability of bouncing and also bounce the farthest (Crease et al., 1991). This combination of factors suggests that the losses resulting from runoff will be greater in a crop with a denser foliage. Because no collectors were placed offtarget, this statement cannot be supported with off-target collector data or depositions from positions 5 and 6 in the high-density crop.

The spray boom applications equipped with extended-range flat fan nozzles or hollow cone nozzles showed fairly uniform distribution of the spray among the different collectors in both crops (Figs. 4 and 5). One can therefore safely assume that these techniques are best suited for applications in a higher density crop. Of the tested nozzles, the extended-range flat fan performed slightly better in both cases.

Spray depositions onto the wooden frame. The techniques also differed in terms of absolute deposits on the frame $\left[\mathrm{F}_{(5,95)}=9.71\right.$; $P<0.01$ ] (Fig. 7). Similarly, for relative spray deposits, these differences were not significant $\left[\mathrm{F}_{(5,95)}=1.95 ; P=0.17\right]$. This indicates that the observed differences between the techniques can mainly be attributed to differences in spray volume. Because all 
techniques resulted in a relative deposition that was statistically the same, no positive effect of an increase of spray pressure or spray volume was found.

In terms of the spatial distribution (graphs made using Simaplot 12.0; Systat Software Inc., Chicago, IL) of the various applications, spray guns 1 and 3 clearly produce a less uniform distribution over the frame (Fig. 7). The spray boom applications and spray gun 2 resulted in a more equal distribution of the spray over the frame despite the two runs used for each spray boom application and the inexperience of the operator of spray gun 2 .

The results of the frame deposition also show that spray gun applications can be optimized by using a lower spray pressure (less than $700 \mathrm{kPa}$ ), a low-capacity nozzle type or gun, and a low application speed (less than $1 \mathrm{~km} \cdot \mathrm{h}^{-1}$ ).

\section{Conclusion}

The results of this study illustrate that crop density affects spray deposition results. With a low crop density, the spray guns performed best, but their advantage disappeared in a crop with a higher crop density. The number of ornamental plants grown $/ \mathrm{m}^{2}$ has increased in the past decade (the Research Center for Ornamental Crops, Destelbergen, Belgium, personal

\section{Spray boom 1}

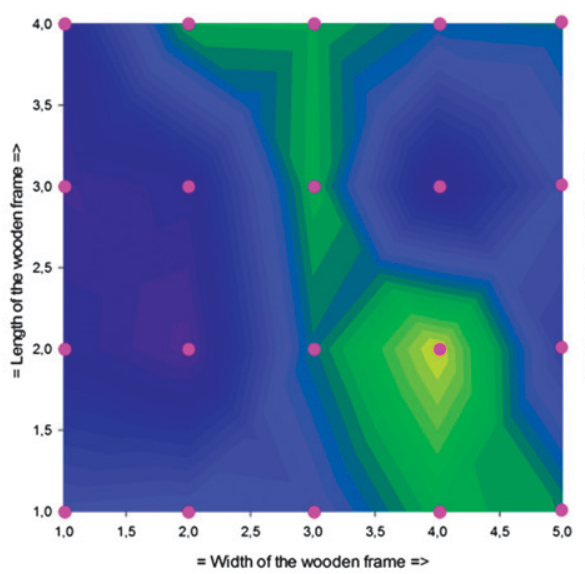

Spray Gun 1

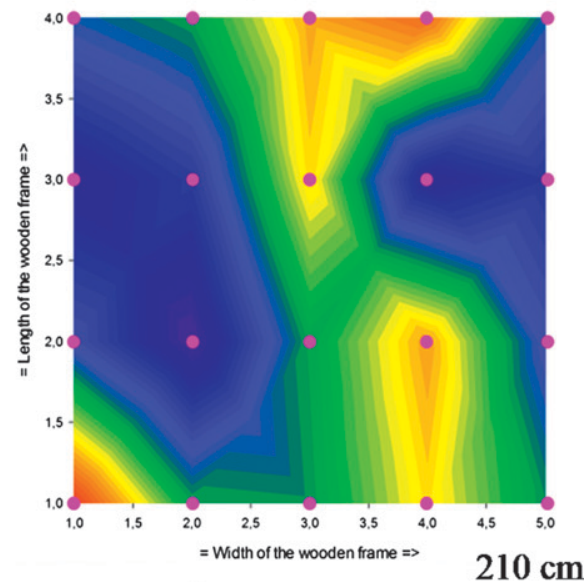

Spray boom 2

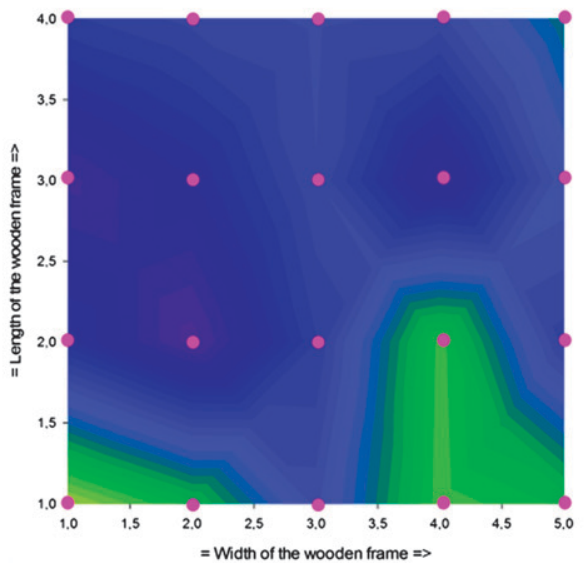

Spray Gun 2

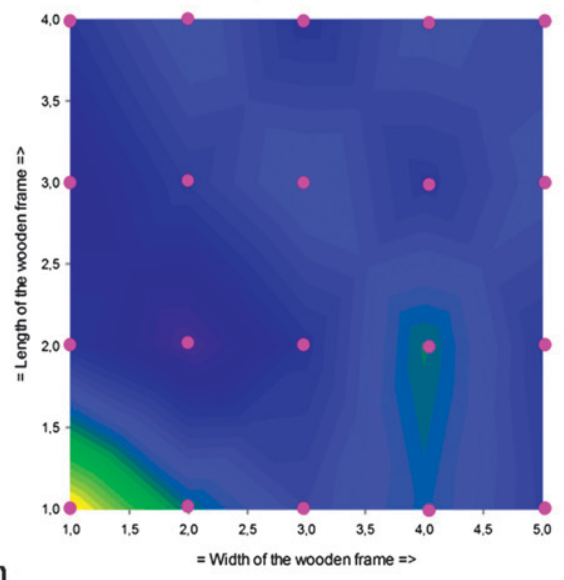

Spray boom 3

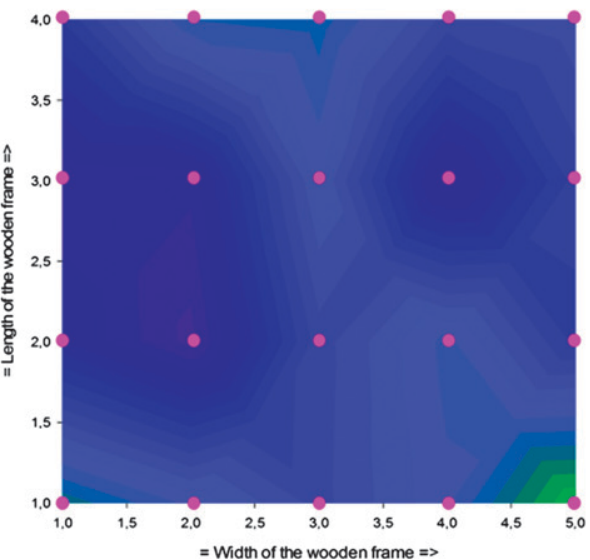

Spray Gun 3

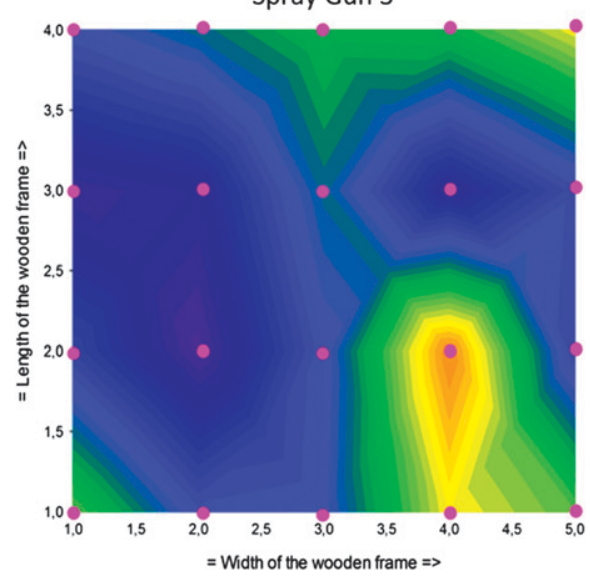

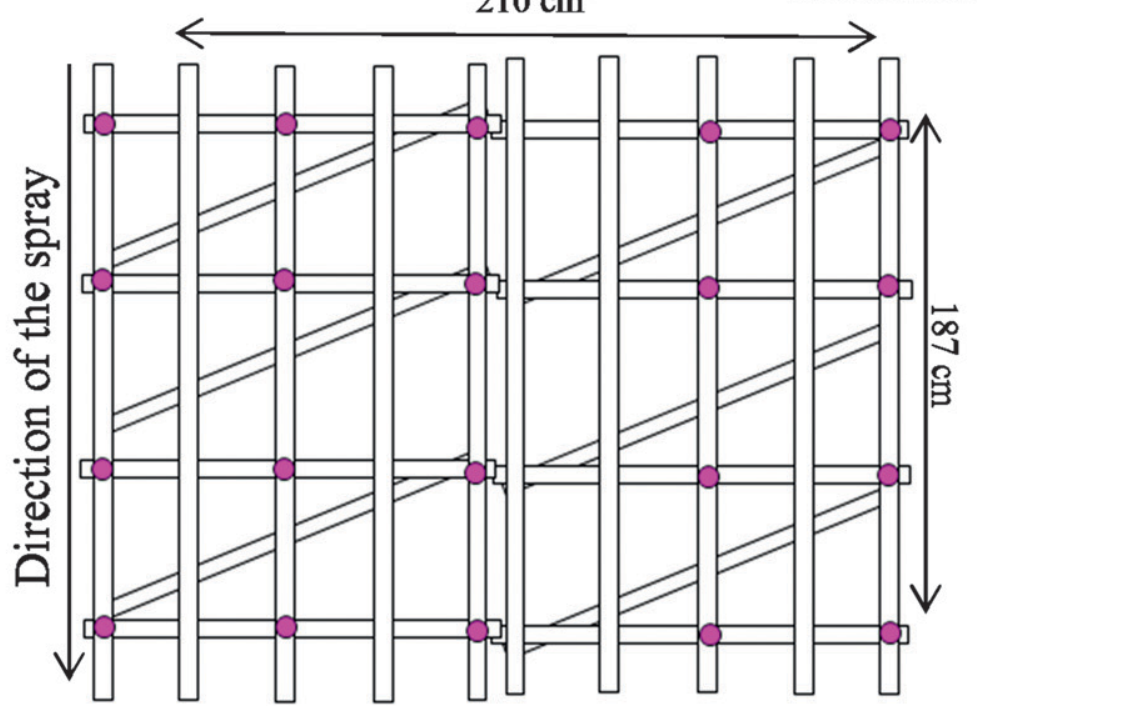

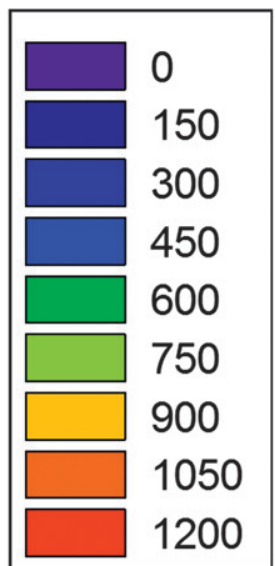

Fig. 7. Absolute depositions $\left(\mathrm{L} \cdot \mathrm{ha}^{-1}\right)$ on the frame collectors. The fuchsia dots in the graphs represent the location of the collectors on the frame. The Y-axis represents the length of the frame; the $\mathrm{X}$-axis represents the width. 
communication). Therefore, under typical growing conditions, standard spray boom applications, especially when equipped with an extendedrange flat fan nozzle, will result in depositions equal to those made with a spray gun.

It should be mentioned, however, that the biggest differences between the two crop densities were noted on collectors oriented upward, whereas little changed in terms of depositions made to the other collector positions. Previous laboratory tests (Foqué and Nuyttens, 2011a, 2011b) indicate that the boom applications can be optimized further by using air support and an appropriate spray angle. This is especially applicable to the depositions on the underside of the leaves and locations in the lower crop zones. These optimizations would further increase the superiority of the spray booms as compared with spray guns.

All spray gun applications were found to be statistically equal and both applications with higher pressure and application rates resulted in a less uniform distribution. One can therefore conclude that using high spray pressure and volume often results in less favorable spray results. Other authors report that spray guns produced less homogeneous spray results (Braekman et al., 2009, 2010; Derksen et al., 2010; Langenakens et al., 2002; Moltó et al., 2000; Nuyttens et al., 2004, 2009a; SánchezHermosilla et al., 2011). Furthermore, literature demonstrates that a higher spray pressure or higher spray application rate produced either no effect or even a negative effect on pest control (Braekman et al., 2009, 2010; Derksen et al., 2001, 2008, 2010; Knewitz et al., 2003; Nuyttens et al., 2009b; Zhu et al., 2005). Despite this growing body of evidence, many greenhouse growers still believe that using their spray guns at a high spray volume and pressure is the only way to assure good plant protection. More training and demonstrations are needed to convince them of the disadvantages of this practice. In Belgium, the dose rate is often expressed as a concentration rather than a maximum amount of product that can be applied to a surface, which places Belgian ornamental growers at high risk for pesticide overuse and unnecessary operator exposure.

The results of these experiments also suggest that spray gun applications can be optimized by using a lower traveling speed (less than $1 \mathrm{~km} \cdot \mathrm{h}^{-1}$ ). To maintain the same application volume, a lower capacity nozzle type or spray gun should be used. The lower traveling speed will increase the workload, however.

In contrast, spray booms always resulted in a more uniform liquid distribution, even when higher traveling speeds were used. This was true for all spray boom applications, and because two runs were made with each spray boom technique, the spray booms showed high repeatability. This proves that spray boom systems have the potential to reduce the workload and increase the efficiency of pesticide applications. Furthermore, the risk of operator exposure can be reduced either by pulling a small spray boom or automating the spraying process (Nuyttens et al., 2009a).

Overall, these results indicate that manually pulled spray booms can assure uniform liquid distribution. Furthermore, manually pulled spray booms cost less than their automated counterparts and they can easily be constructed by the growers themselves. This makes them easily adaptable to each grower's needs. The use of spray booms in ornamental crops has great potential to improve on the more commonly used spray gun applications. Spray booms offer more uniform coverage, better deposition, reduced pesticide runoff to the environment, and reduced risk of operator exposure to pesticides.

\section{Literature Cited}

Braekman, P., D. Foqué, W. Messens, M.-C. Van Labeke, J.G. Pieters, and D. Nuyttens. 2010. Effect of spray application technique on spray deposition in greenhouse strawberries and tomatoes. Pest Manag. Sci. 66:203-212.

Braekman, P., D. Foqué, M.-C. Van Labeke, J.G. Pieters, and D. Nuyttens. 2009. Influence of spray application technique on spray deposition in greenhouse ivy pot plants grown on hanging shelves. HortScience 44:1921-1927.

Braekman, P. and B. Sonck. 2008. A review of the current spray application techniques in various ornamental plant productions in Flanders. Belgium. Proc. Aspects Appl. Biol. 84:303308.

Crease, G.J., F.R. Hall, and J.R.M. Thacker. 1991 Reflection of agricultural sprays from leaf surfaces. J. Environ. Sci. Health, Part B: Pestic., Food Contam. Agr. Wastes 26:383-407.

Derksen, R.C., J. Frantz, C.M. Ranger, J.C. Locke, H. Zhu, and C.R. Krause. 2008. Comparing greenhouse handgun delivery to poinsettias by spray volume and quality. Trans. ASABE 51: $27-33$

Derksen, R.C., S.A. Miller, H.E. Ozkan, and R.D Fox. 2001. Spray deposition characteristics on tomatoes and disease management as influenced by droplet size, spray volume, and airassistance. Proc. ASAE Annu. Mtg. Paper No. 011120

Derksen, R.C., C.M. Ranger, L.A. Cañas, J.C Locke, H. Zhu, and C.R. Krause. 2010. Evaluation of handgun and broadcast systems for spray deposition in greenhouse poinsettia canopies. Trans. ASABE 53:5-12.

Foqué, D. and D. Nuyttens. 2010. Optimization of the spraying equipment and technology used in ornamental crops. Commun. Agr. Appl. Biol. Sci. 75:147-156.

Foqué, D. and D. Nuyttens. 2011a. Effects of nozzle type and spray angle on spray deposition in ivy pot plants. Pest Manag. Sci. 67:199-208.

Foqué, D. and D. Nuyttens. 2011b. Effect of air support and spray angle on coarse droplet sprays in ivy pot plants. Trans. ASABE 54: 409-416.
Foqué, D., P. Braekman, J.G. Pieters, and D. Nuyttens. 2011c. A vertical spray boom application technique for conical bay laurel (Laurus nobilis) plants. Crop Prot. (submitted).

González, R., F.S. Rodríguez, J. Sánchez-Hermosilla, and J.G. Donaire. 2009. Navigation techniques for mobile robots in greenhouses. Appl. Eng. Agr. 25:153-165.

Goossens, E., S. Windey, and B. Sonck. 2004. Information service and voluntary testing of spray guns and other types of sprayers in horticulture. Proc. Aspects Appl. Biol. 71:41-48.

Knewitz, H., H. Koch, and F. Lehn. 2003. Einsatz eines Düsenverbandes und flächenbezogene Dosierung bei der Anwendung von Pflanzenschutzmitteln im Gewächshaus. Gesunde Pflanz. 55:70-76.

Langenakens, J., G. Vergauwe, and A. De Moor. 2002. Comparing hand-held spray guns and spray booms in lettuce crops in a greenhouse. Proc. Aspects Appl. Biol. 66:123-128.

Moltó, E., B. Martín, and A. Gutiérrez. 2000. Pesticide loss reduction by automatic adaptation of spraying on globular trees. J. Agr. Eng. Res. 78:35-41.

Nuyttens, D., P. Braekman, S. Windey, and B. Sonck. 2009a. Potential dermal pesticide exposure affected by greenhouse spray application technique. Pest Manag. Sci. 65:781-790.

Nuyttens, D., P. Braekman, and D. Foqué. 2009b. Optimization of the spray application technology in bay laurel (Laurus Nobilis). Commun. Agr. Appl. Biol. Sci. 74:85-90.

Nuyttens, D., S. Windey, and B. Sonck. 2004. Optimisation of a vertical boom for greenhouse spray applications. Biosystems Eng. 89:417423.

Sánchez-Hermosilla, J., R. Medina, and J.C. G'Azquez. 2003. Improvements in pesticide application in greenhouses, p. 54-61. In: Balsari, P., G. Doruchowski, and J.V. Cross (eds.). Proc. VIIth Workshop on Spray Application Technique in Fruit Growing, Cuneo, Italy. Universita degli Studi Torino, Grugliasco, Italy.

Sánchez-Hermosilla, J., V.J. Rincón, F. Páez, F. Agüera, and F. Carvajal. 2011. Field evaluation of a self-propelled sprayer and effects of the application rate on spray deposition and losses to the ground in greenhouse tomato crops. Pest Mgt. Sci. 67:942-947.

Subramanian, V., T.F. Burks, and S. Singh. 2005. Autonomous greenhouse sprayer vehicle using machine vision and laser for steering control. Appl. Eng. Agr. 21:935-943.

Vidal, J.L.M., F.J.E. Gonzalez, A.G. Frenich, M.M. Galera, P.A. Aguilera, and E.L. Carrique. 2002. Assessment of relevant factors and relationships concerning human dermal exposure to pesticides in greenhouse applications. Pest Manag. Sci. 58:784-790.

Vissers, M. 2005. Intern verslag enquête sierteelt 'Enquête spuittechniek insecticiden 2004 Proefcentrum voor Sierteelt (PCS), Destelbergen, Belgium.

Zhu, H., R.C. Derksen, C.R. Krause, R.D. Brazee, R.D. Fox, M.E. Reding, R.H. Zondag, and H.E Ozkan. 2005. Spray deposition and off-target loss in nursery tree crops with conventional nozzle, air induction nozzle and drift retardant. Proc. ASAE Annu. Mtg. Tampa, FL. Paper No. 051007. 